\title{
Polychaete Annelid Biomass Size Spectra: The Effects of Hypoxia Stress
}

\author{
Fangyuan Qu, ${ }^{1,2}$ Clifton Nunnally, ${ }^{3}$ and Gilbert T. Rowe $e^{1,4}$ \\ ${ }^{1}$ Department of Oceanography, Texas A\&M University, College Station, TX 77843, USA \\ ${ }^{2}$ The First Institute of Oceanography, State Oceanic Administration, No. 6 Xianxialing Road, Qingdao 266061, China \\ ${ }^{3}$ Department of Oceanography, University of Hawaii, Manoa, HI, USA \\ ${ }^{4}$ Department of Marine Biology, Texas AઐM University at Galveston, Galveston, TX 77553, USA
}

Correspondence should be addressed to Gilbert T. Rowe; roweg@tamug.edu

Received 4 July 2015; Revised 28 September 2015; Accepted 30 September 2015

Academic Editor: Garth L. Fletcher

Copyright (C) 2015 Fangyuan Qu et al. This is an open access article distributed under the Creative Commons Attribution License, which permits unrestricted use, distribution, and reproduction in any medium, provided the original work is properly cited.

\begin{abstract}
Quantitative benthic samples were taken during spring and summer at three locations on the Louisiana continental shelf from 2004 to 2012 to assess the influence of hypoxia on the mean sizes (wet weight) of polychaete annelid worms. While the mean body size over the entire study of 64 samples was $3.99 \pm 4.66 \mathrm{mg}$ wet weight per individual, the mean ranged from $2.97 \pm 2.87 \mathrm{mg}$ during consistently hypoxic conditions $(<2 \mathrm{mg} / \mathrm{L})$ to a high of $7.13 \pm 7.60 \mathrm{mg}(p<0.01)$ under oxic conditions $(>2 \mathrm{mg} / \mathrm{L})$. The variations in size within assemblages were estimated from conventional biomass size spectra (BSS) and normalized biomass size spectra (NBSS) across a broad range of oxygen concentrations. The decline in size was due to the elimination of large species under hypoxic conditions $(<2 \mathrm{mg} / \mathrm{L})$, not a reduction in size within species. At "severe" levels of hypoxia $(<1 \mathrm{mg} / \mathrm{L})$, the smallest species also declined in abundance, whereas the ubiquitous "medium-sized" Paraprionospio pinnata flourished. These results suggest that there will be enhanced selection for small sizes and species with enlarged branchial palps such as those in P. pinnata if, as predicted, hypoxia becomes more commonplace in time and space worldwide.
\end{abstract}

\section{Introduction}

The northern Gulf of Mexico continental shelf just to the west of the Mississippi River Delta experiences widespread hypoxia seasonally $[1,2]$. Hypoxia (dissolved oxygen < $2 \mathrm{mg} / \mathrm{L}$ ) results from two synergistic factors: the summer vertical stratification of the water column that prevents the mixing of oxygen into deep water [3-5] and the demand for oxygen by the decomposition of organic matter below the pycnocline $[1,6]$. Since the benthic infauna is less mobile than demersal crustaceans and fishes, they are "trapped" in deep and near-bottom water and thus susceptible to low oxygen stress. The negative effects of hypoxia on coastal benthos (decline of biodiversity, abundance, biomass, and bioturbation) have been broadly recognized [7-9]. Many of the few species that can survive intermittent low oxygen stress are small polychaete annelid worms, the most common taxon among all benthic macrofauna [10,11], but we know little about how these organisms are able to persist under such stress [12].
Body size is a quantifiable trait that reflects a species' evolution and ecological relationships [12-16]. Food availability [17], temperature [18], depth [19, 20], latitude [21], and even oxygen levels [22], among others, are assumed to affect body size. The potential relationship between oxygen and body size has been investigated across a wide range of taxa [23-26].

It is reasonable that smaller animals with large surface area to volume ratios would be better able to absorb oxygen in low concentrations [27]. It has also been suggested that small organisms may be less vulnerable to disturbance because of their high reproductive rate and diminished demand for resources [28]. Thus we are suggesting that small size in the polychaetes may be one trait that allows them to persist during hypoxic conditions. To pursue this idea, we have generated a set of data on polychaete sizes encountered across an extreme range of interannual and seasonal oxygen concentrations.

The relationship between size and low oxygen stress is not necessarily simple and direct. The stress could eliminate 
large species in general, leaving only small species to survive. Alternatively, size could decline within a species, or, given wide and divergent functional morphology within the entire taxa, the survival may be independent of size. The survivors may possess some morphological or physiological talents that make them capable of utilizing oxygen at very low concentrations $[29,30]$.

Generation of biomass size spectra (BSS) is a simple, timesaving way to compare the structure of assemblages or populations [31], a method first proposed by Sheldon and Parsons [32] for particulate matter. Size spectra of populations [33] and assemblages [34] have historically provided significant insights into growth rates and secondary production, especially within the benthos. Size spectra have provided insights on survival in stressful habitats, such as oxygen minimum zones (OMZ) $[34,35]$.

Variations in configuration and shape of simple size distribution spectra are sometimes difficult to quantify and compare [36]. To obviate this problem, Platt and Denman [37, 38] suggested constructing "normalized biomass size spectra" (NBSS) that would facilitate comparisons of size distributions between different communities [36]. We have therefore included NBSS plots as an alternative option for characterizing size structure within our assemblages.

For most animal communities, NBSS is a linear plot of the total biomass as a function of narrow size categories of NBSS, from small to large organisms on the $x$-axis. A negative slope represents abundant but small organisms with relatively high total biomass down to large organisms that are fewer in number and lower in total biomass. The greater the dominance of the small size classes, the steeper the negative slope.

The slope and intercept of an NBSS regression line have been utilized previously in comparisons of the size structure of communities from different habitats $[14,34]$. For example, a steep slope of the regression illustrates an assemblage dominated by small-sized organisms compared to a modest slope that reflects a higher frequency of larger individuals. Thus, according to the Pearson and Rosenberg [39] model, a community dominated by small opportunists following a disturbance would have a steep slope but the slope would rise during recovery as the small, fast growing opportunists are replaced by larger, more slowly growing species. In general, the intercept and the height of the regression line above the $x$-axis are a function of total biomass. It has been suggested that the departure from a statistically significant negative regression is a departure from steady state [31, 36, 40, 41].

In this paper, we will (1) compare bottom water oxygen concentrations in spring and summer at three standard locations along a $50 \mathrm{~km}$ long transect within a narrow depth range (11 to ca. $20 \mathrm{~m}$ ) in the northern Gulf of Mexico; (2) construct polychaete size spectra from benthic samples subjected to different oxygen concentrations at each of the locations; and (3) compare biomass size spectra (BSS) and normalized biomass size spectra (NBSS) among assemblages at different oxygen concentrations. This comparison is intended to provide insights into the influence of seasonal hypoxia on polychaete body size structure under (a) oxic ( $>2 \mathrm{mg} / \mathrm{L})$, (b) hypoxic $(<2 \mathrm{mg} / \mathrm{L})$, and $(\mathrm{c})$ severely hypoxic $(<1 \mathrm{mg} / \mathrm{L})$ conditions.
TABLE 1: Sampling locations and depths of each site.

\begin{tabular}{lccc}
\hline & Location & Depth $(\mathrm{m})$ & Cruises \\
\hline A & $28.97 \mathrm{~N}, 89.49 \mathrm{~W}$ & 11.2 & '04 to '09 \\
B & $28.87 \mathrm{~N}, 90.38 \mathrm{~W}$ & 20.3 & '04 to '12 \\
C & $29.00 \mathrm{~N}, 92.01 \mathrm{~W}$ & 19.5 & '04 to '12 \\
AB5 & $29.08 \mathrm{~N}, 89.95 \mathrm{~W}$ & 18.0 & '09 \& '12 \\
\hline
\end{tabular}

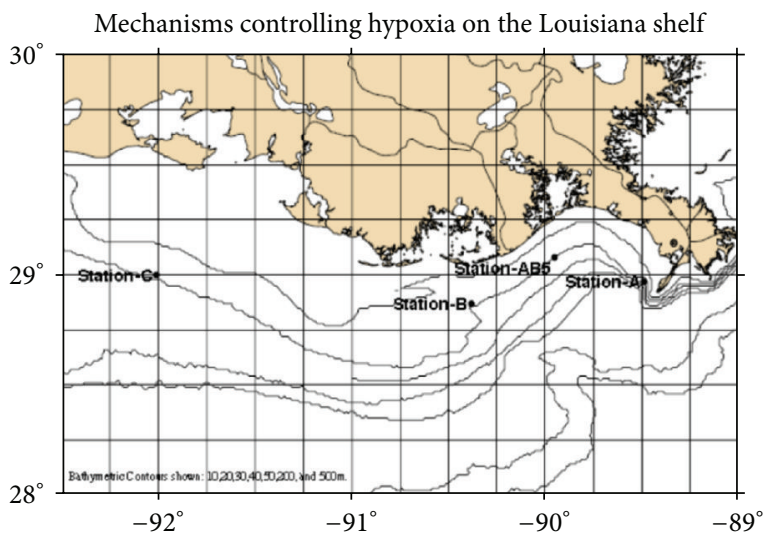

FIgURE 1: Sampling sites in Gulf of Mexico hypoxic zone on Louisiana continental shelf.

\section{Methods}

2.1. Sampling Strategies. The sampling in this study began in 2004 and extended somewhat irregularly until 2012. Stations were placed close to the Mississippi River Birdfoot Delta on the continental shelf (Figure 1, A) and extended to the west between the 10 to $20 \mathrm{~m}$ isobaths (Figure 1, C). This pattern followed sampling sites occupied by the Mechanisms Controlling Hypoxia (MCH) project that has attempted to make consistent, repeated sampling of the same locations from early spring, with the onset of stratification, through to late summer, when hypoxia and stratification are often most intense (Figure 1 and Table 1). The locations were designed to compare the intensity and the causes of hypoxia at what has been termed the "brown" water zone close to the river mouth (A), the "green" water zone with high concentrations of plant biomass just to the west of the brown water (B), and the "blue" water zone further to the west of $\mathrm{B}$, where the water column is comparatively more transparent $(\mathrm{C})$; these zones were more or less evenly placed along the extension of the river plume as it flows and disperses from east to west [42], as proposed by Rowe and Chapman [5]. The purpose of this abbreviated pattern in time and space was to observe the setup of the physical stratification in spring that prevents deep water from becoming oxygenated $[43,44]$ and thus leads to eventual hypoxia by summer. A somewhat similar line of sampling locations has been used to assess the effects of hypoxia on polychaete trophic structure [45], biogenic structures within the sediments [46], and sediment erodibility [47], but in slightly deeper water.

Oxygen concentrations in the water column were profiled using a SeaBird 911 CTD from the surface to 1 to 2 meters above bottom. The CTD was equipped with a SB43 oxygen 
electrode, as well as conductivity and thermistor probes. A rosette of 12 Niskin bottles caught individual water samples that were analyzed for plant pigments, salinity, dissolved oxygen, and inorganic nutrients [48]. Near-bottom (ca. < $0.5 \mathrm{~m}$ ) water samples were taken using a four-bottle sampler that tripped when a trigger weight encountered the mud. $\mathrm{MCH}$ data are available through NODC under Accession number 0088164.

Three subcores (pseudoreplicates) with a diameter of $13.9 \mathrm{~cm}$ each were taken from a single $0.2 \mathrm{~m}^{2}$ GOMEX box corer at each location on each cruise. These subcores were initially incubated for several hours in a water bath aboard ship to determine sediment community oxygen consumption and nutrient regeneration $[49,50]$. The entire volume of sediment of each subcore was then sieved through $0.5 \mathrm{~mm}$ stainless steel mesh to remove the macrofauna. In 2012 three replicate $0.1 \mathrm{~m}^{2}$ GOMEX box cores were taken at sites $\mathrm{B}, \mathrm{C}$, and $\mathrm{AB}$, an intermediate site added in 2009 and 2012 (Figure 1 and Table 1). The surface $15 \mathrm{~cm}$ of each of these was also sieved through $0.5 \mathrm{~mm}$ stainless steel mesh. Following the sieving at sea, all samples were fixed aboard ship with $10 \%$ buffered formalin in filtered sea water.

2.2. Sample and Data Processing. In the lab, the sieved and formalin-fixed biota of the subcore samples were stained with several $\mathrm{mL}$ of $5 \%$ Rose Bengal for 24 hours and the stained invertebrates were sorted to the lowest possible taxonomic level using a dissecting microscope. Samples were preserved in $70 \%$ ethyl alcohol following sorting. The sorted polychaete annelid (segmented worm) fractions were then sorted again to the identified species (species list available in Supplemental Information or from the authors, on request) (see Supplementary Material available online at http://dx.doi.org/ $10.1155 / 2015 / 983521$ ). The 64 samples were subcores (pseudoreplicates) from 25 box cores and thus the three subcores were aggregated into a single sample from a location. Thus, the species-sample matrix contained 25 samples containing a total of 146 separate polychaete species.

Total wet weight $(\mathrm{mg})$ of each polychaete species was obtained by weighing the sorted samples on a Sartorius CP2P and OHAUS AS260D balance after blotting on a paper towel for 30 seconds. Mean body weight of individuals of each "small" species in each subcore was then calculated by dividing the total weight of the species by the number of individuals in the subcore. Individuals of large species were weighed separately.

A species-sample matrix was constructed and the species abundance data were fourth-root transformed prior to multivariate analyses. CLUSTER was carried out using PRIMER 6.0. SIMPROF (Similarity Profile) was used simultaneously with CLUSTER to test the significance $(p<0.05)$ of differences between clusters [51]. SIMPER estimated the contribution of each species to a faunal group and the contribution of each species to the dissimilarity between faunal groups. The species that contributed the most to a group was considered a "characteristic" species [52]. Regressions were drawn by SigmaPlot 10.0 and Excel 2007. Best-fit regression models were chosen based on the adjusted $R^{2}$ and numbers of variables. Significant differences between the mean abundances were assessed with a one-way analysis of variance (ANOVA).

Biomass size spectra (BSS) and normalized biomass size spectra (NBSS) were constructed in 14 logarithmic $\left(\log _{2}\right)$ biomass (mg wet weight) size classes. These size classes are aligned along the $x$-axis as the "independent" variable. NBSS is a graph of the biomass of a size category $[m(s)]$ divided by the "width" of that size category ( $\Delta s$ is the difference between the upper and lower boundaries of the size class) in $\log _{2}$ units on the dependent or $y$-axis as a function of the size categories in $\log _{2}$ units on the independent or $x$-axis. In the figures, we represented $m(s) / \Delta s$ as $M(s)$; that is, $M(s)=m(s) / \Delta s$ $[37,38]$. Analysis of covariance (ANCOVA) was used to test the significance of differences of the slope and intercept of the NBSS linear regression lines. All statistical tests were performed with SPSS 17.0.

\section{Results}

3.1. Oxygen Concentrations. Oxygen in the bottom water varied appreciably over the course of the sampling (Figure 2): 12 were oxic and 12 were hypoxic. In April 2004 and March 2007 all three sites were oxic. On the other hand, in June 2004 and August 2004 all three sites were hypoxic. At the other locations and times the sites were mixed, but not in a predictable fashion. In March 2005 the middle site B was hypoxic but $\mathrm{A}$ and $\mathrm{C}$ were not; by May 2005 the site closest to the river (A) had dropped to the hypoxic boundary but mid-site $B$ had risen into oxic concentrations. The last three samplings were separated by several years each and exhibited a wide range of conditions: totally oxic in March 2007, three of four locations hypoxic in August 2009, and two of three sites hypoxic in August 2012. A nearshore site, AB5, added in late summer of 2009 and 2012, was always hypoxic; the most distal location, C, was always oxic from 2007 to 2012. The highest single concentration overall was $6.76 \mathrm{mg} / \mathrm{L}$ at the most distant site in early spring (C, March 2007), whereas the lowest was $0.12 \mathrm{mg} / \mathrm{L}$ in late summer (B and AB5, August 2009). In general, as expected, higher values were located at the greatest distance from the river $(\mathrm{C})$ during spring (March and April), whereas the lowest were in mid- to late summer and close to the river (A, AB5, and B). There were however some persistent exceptions. Likewise, there was not a consistent spatial pattern. (It should be noted that variations in oxygen concentration in time and space have been the subject of numerous publications, especially near sites $\mathrm{B}$ and $\mathrm{AB} 5$, for several decades $[1,2,46,47,53,54]$.) All $\mathrm{MCH}$ data are available through NODC under Accession number 0088164.

3.2. Distribution of Mean Animal Sizes. The mean abundance of polychaetes in all 64 subcores was 2746 ind. polychaetes $/ \mathrm{m}^{2}(\sigma= \pm 2258)$, and these amounted to $6.9 \mathrm{gm}$ wet weight $/ \mathrm{m}^{2}(\sigma= \pm 5.3)$. There was a significant relationship between mean body size and bottom oxygen concentration (Figure 3): higher oxygen meant bigger worms. Mean body size ranged from $0.6 \mathrm{mg}$ to $30 \mathrm{mg}$, with an average value of $3.99 \mathrm{mg}$ per worm $(\sigma= \pm 4.7)$. The highest mean size $(30 \mathrm{mg})$ 


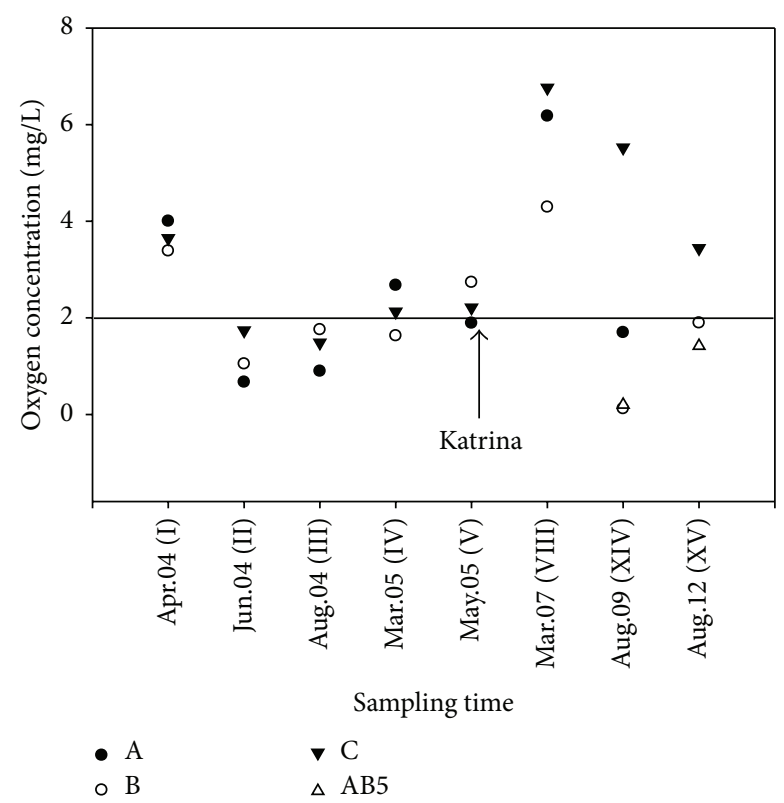

Figure 2: Near-bottom oxygen concentrations at each sampling site (A, B, C, and AB5 in Figure 1) from April 2004 to August 2012, with the horizontal line indicating the $2 \mathrm{mg} / \mathrm{L}$ hypoxia threshold. Concentrations below $2 \mathrm{mg} / \mathrm{L}$ were considered hypoxic, whereas those below $1 \mathrm{mg} / \mathrm{L}$ were categorized as "severe hypoxia." "Katrina" was a major hurricane that passed through the area several months after the 2005 sampling.

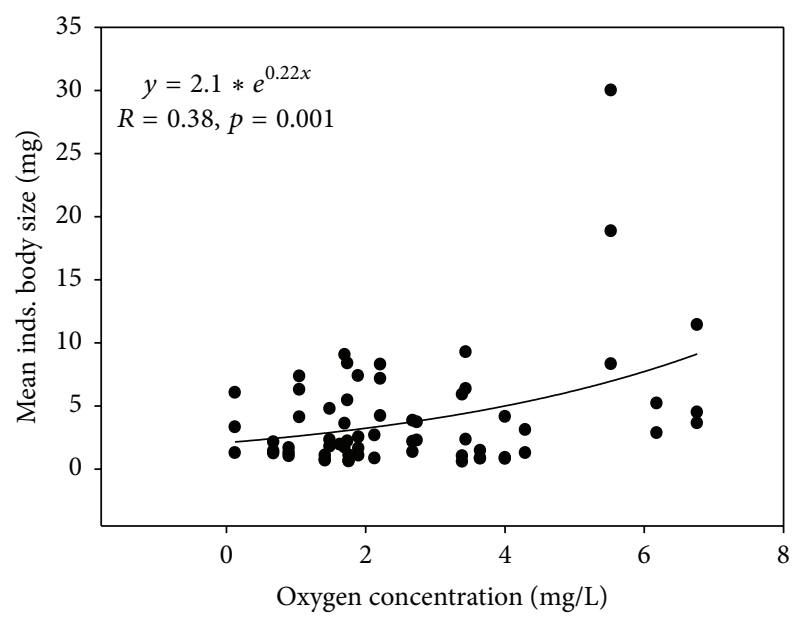

Figure 3: Exponential relationship between mean body size of polychaetes and bottom oxygen concentration at each of the 64 sites (A, B, C, and AB5 in Figure 1) in all cruises. The highest three biomass mean values at $5.76 \mathrm{mg} / \mathrm{L}$ contained the bamboo worms sampled in August 2009 (see Figure 2 and text).

was sampled in August 2009 and included the large bamboo worms Clymenella torquata and Asychis elongatus.

Throughout most of the early sampling period (2004-05), the average body size of the polychaete populations sampled was $2.97 \mathrm{mg}$ wet weight $(\sigma= \pm 2.87)$; however in $2007-09$ the total mean body size rose to $7.13 \mathrm{mg}(\sigma= \pm 7.60)(p<0.01)$. By 2012 , this value dropped back to $2.85 \mathrm{mg}(\sigma= \pm 2.97)$, but this

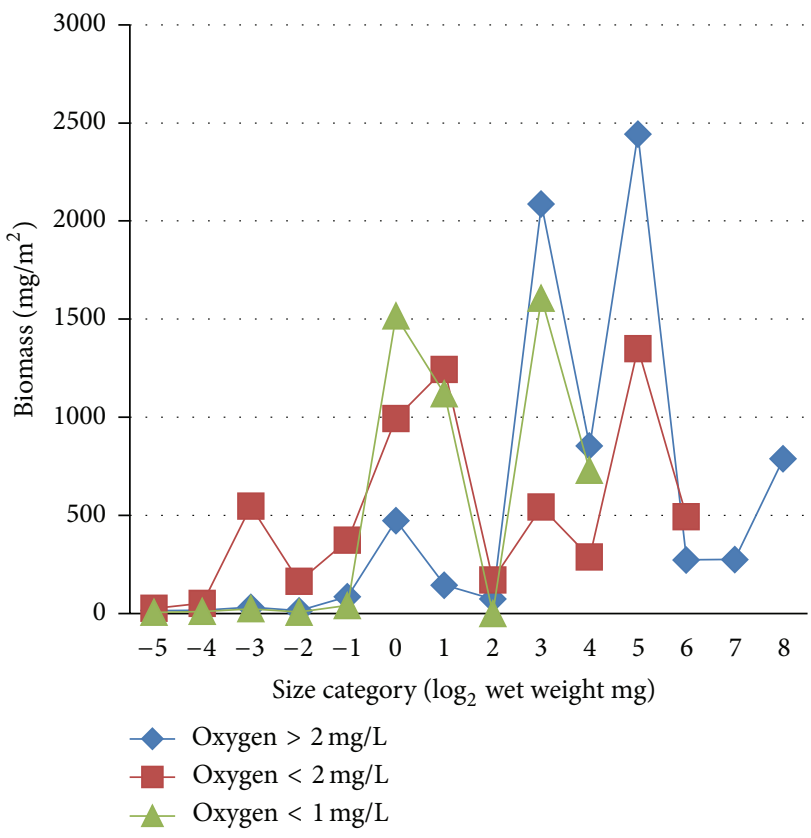

FIGURE 4: Polychaete biomass size structure (BSS) under different oxygen concentrations, as indicated. The $y$-axis is total wet weight biomass under each line; the $x$-axis is the size categories, as indicated.

latter mean was not significantly different $(p>0.05)$ from any of the prior values.

The overall mean biomass was $6.9 \mathrm{gm}$ wet weight $/ \mathrm{m}^{2}(\sigma=$ $\left.\pm 5.2 \mathrm{gm} / \mathrm{m}^{2} ; n=64\right)$ for the entire study. If the entire set of samples is arbitrarily divided into three time blocks (2004-05, 2007-09, and 2012), the mean of the total wet weight biomass for all the polychaetes was 7.6 $(\sigma= \pm 5.9), 6.3(\sigma= \pm 4.4)$, and $4.7(\sigma= \pm 2.7) \mathrm{g} / \mathrm{m}^{2}$, but these were not statistically different $(p>0.05)$. Thus, while sizes may have decreased in hypoxic conditions, the total biomass remained relatively high at $6.9 \mathrm{gm}$ wet weight $/ \mathrm{m}^{2}$ and did not vary consistently.

The overall mean abundance was 2,747 ind. $/ \mathrm{m}^{2}(\sigma=$ $\pm 2259 ; n=64)$. During the early intense hypoxia this was $3321(\sigma= \pm 2447)$ inds. $/ \mathrm{m}^{2}$, whereas abundance went down to $1246 \pm 1072$ inds. $/ \mathrm{m}^{2}$ in the sampling two years later (2007 to $2009, p<0.01)$. Seven years later (2012) abundance was at an intermediate level (2226 inds. $/ \mathrm{m}^{2}, \sigma= \pm 1049$ inds. $/ \mathrm{m}^{2}$ ).

3.3. Biomass Size Spectra (BSS, Figure 4). The biomass size spectra have been plotted at the three different categories of oxygen concentration: oxic, hypoxic, and severely hypoxic (Figure 4 ). When oxygen was higher than $2 \mathrm{mg} / \mathrm{L}$, large worms were present in size classes 7 (64-128 mg) and 8 (128$256 \mathrm{mg}$ ). When oxygen concentration was lower than $2 \mathrm{mg} / \mathrm{L}$, species in size classes 7 and 8 disappeared, but when oxygen dropped down below $1 \mathrm{mg} / \mathrm{L}$, another two size classes ( 5 and 6) also disappeared. That is, ultimately, there were no big worms when oxygen was severely low. On the other hand, the smallest worms in the tiniest sizes were eliminated too (size classes -1 down to -5 ), leaving only intermediate sized species (size classes 0 to 4 ). 


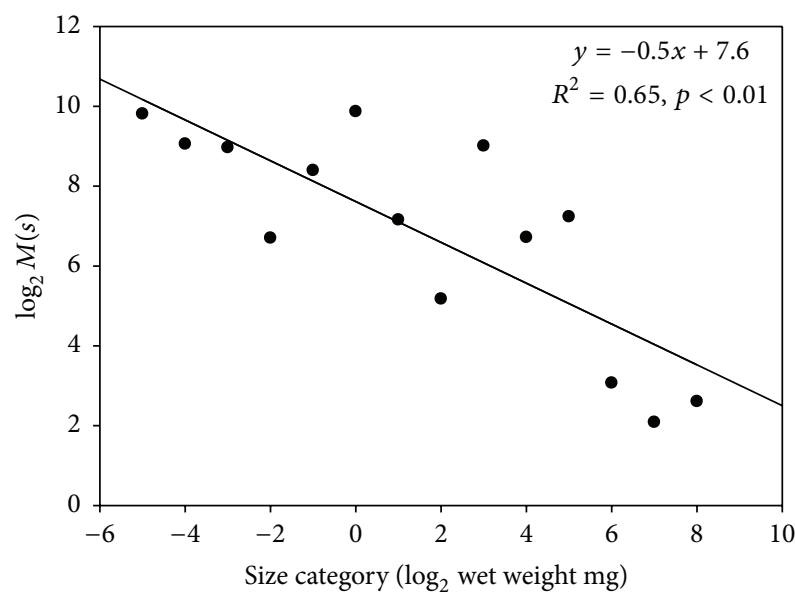

(a) $($ Oxygen $>2 \mathrm{mg} / \mathrm{L})$

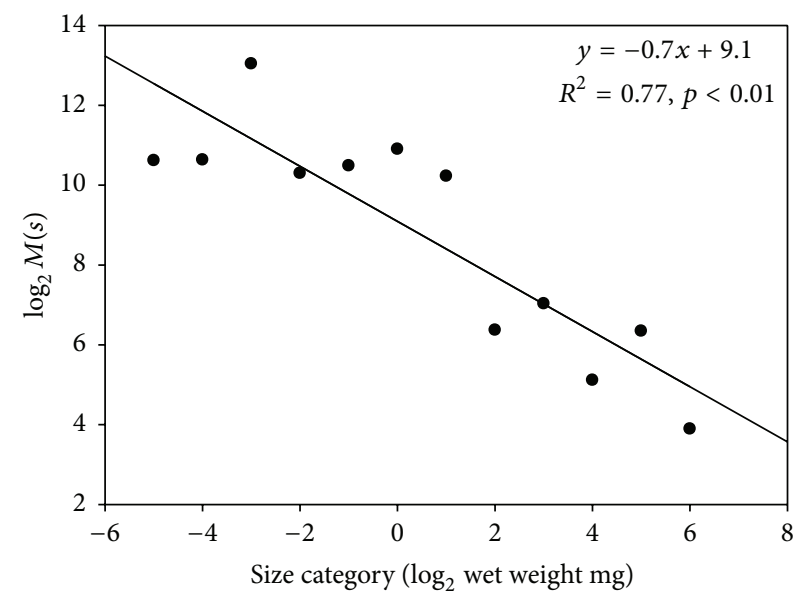

(b) $($ Oxygen $<2 \mathrm{mg} / \mathrm{L})$

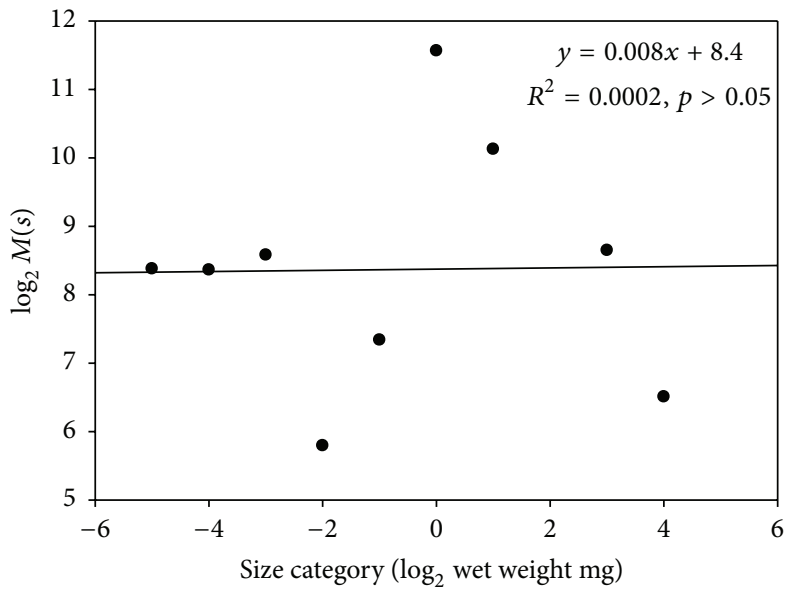

(c) $($ Oxygen $<1 \mathrm{mg} / \mathrm{L})$

Figure 5: Normalized biomass size spectra (NBSS; see text) under different oxygen concentrations: (a) oxygen concentration $>2$ mg/L; (b) $<2 \mathrm{mg} / \mathrm{L}$; and $(\mathrm{c})<1 \mathrm{mg} / \mathrm{L}$. Note the differences in axes in each graph.

The three spectra had some similar peaks within the same size classes ( 0,3 , and 5 , Figure 4$)$; the exception was the large numbers in very small size class $(-3)$ at oxygen lower than $2 \mathrm{mg} / \mathrm{L}$ (red line, Figure 4). Species in that size class $(-3)$ were mostly Cossura soyeri, Levinsenia gracilis, Prionospio cristata, and Magelona sp. H. This peak indicates that these relatively small species flourished under moderately hypoxic conditions, but then, as the hypoxia worsened, they declined too (green line).

3.4. Normalized Biomass Size Spectra (NBSS, Figure 5). The slopes of the normalized biomass size spectra (NBSS) of both oxic and hypoxic (oxygen $<2 \mathrm{mg} / \mathrm{L}$ ) conditions were significant $(p<0.05)$ (Figure 5). The slope of hypoxic (oxygen $<2 \mathrm{mg} / \mathrm{L}$ ) NBSS appeared to be slightly more negative than the slope for oxic conditions, but the difference was not significant $(-0.68$ versus $-0.51 ; p>0.05)$. When oxygen was below $1 \mathrm{mg} / \mathrm{L}$, the NBSS regression fit was very low $\left(R^{2} \approx 0\right)$ with no apparent slope $(p>0.05)$. This reflects the elimination of both the largest and the smallest species under these severe conditions.
P. pinnata (size class 0 ) is a medium-sized polychaete and the highest point in the "poor" NBSS plot was in size class 0 , dominated by $P$. pinnata (Table 2 ). When oxygen concentration was high, small-sized species and $P$. pinnata were almost equal in abundance. When oxygen was $<1 \mathrm{mg} / \mathrm{L}$, the percentage of small-sized and large-sized worms both declined, leaving $P$. pinnata to flourish, with abundances four to five times more than the small-sized species. This peak in the middle attributed to $P$. pinnata produced the peculiar nonlinear shape of the NBSS.

3.5. Species Groups Associated with Location, Time, and Hypoxia. Similarity analysis of the entire list of 146 species from all 25 locations was conducted to determine the relationships between species groups, hypoxia, and location along the east to west transect. The 25 samples indicate that there were five faunal groups ( $>40 \%$ similarity; $p<0.05$ ). The largest group of species (beginning on the left of Figure 6) appeared 18 "times" at sites A, B, and C from 2004 through to 2009 in both spring and summer. This demonstrates that the fauna was remarkably uniform in time and space across 
TABLE 2: Percentage of small-sized polychaetes and $P$. pinnata under different times and conditions relative to total abundance.

\begin{tabular}{lcc}
\hline & $\begin{array}{c}\text { \% small-sized } \\
\text { (size classes } \\
-6 \sim-4)\end{array}$ & $\begin{array}{c}\text { \% P. pinnata } \\
(\text { size classes }-1 \sim 1)\end{array}$ \\
\hline $2004-2005$ & 28.7 & 32.5 \\
$2007-2009$ & 8.3 & 34.6 \\
Oxic $(>2 \mathrm{mg} / \mathrm{L})$ & 29.0 & 23.1 \\
Severely hypoxic $(<1 \mathrm{mg} / \mathrm{L})$ & 13.7 & 62.7 \\
\hline
\end{tabular}

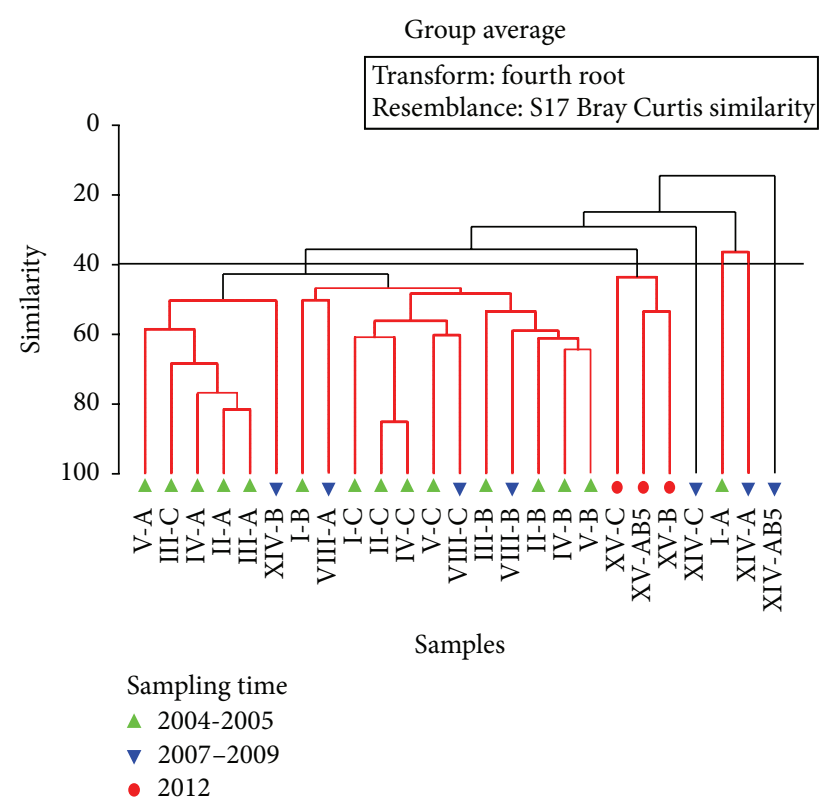

FIgURE 6: Cluster dendrogram with SIMPROF test of all sites sampled from 2004 to 2012. Cruise numbers and site names are shown under each colored symbol ("I-A" means site A in cruise I). Green: 2004-2005, blue: 2007-2009, and red dots: 2012. Red lines mean there was no reliable statistical difference $(p>0.05)$ between the relationships, while black lines indicate significant clusters $(p<$ $0.05)$. At the $40 \%$ similarity level, the samples clustered into 5 groups. See Table 1 for sampling months of cruises I through XIV.

most of the entire study. The other four smaller groups were encountered at only seven times and locations (all on the right in Figure 6). Within those seven, the three samples (in red) taken in August 2012 stood out by themselves. The other three groups included only one or two sites taken in August, with the exception of a single sampling in April at site A adjacent to the river's entrance onto the continental shelf (Figure 6).

The large grouping of species assemblages at all locations and seasons into Group 1 demonstrates that the fauna in general was remarkably uniform; however there is some suggestion that the fauna in Group 1 can be partitioned into subgroups that conform to "zones A, B, and C" as suggested in Rowe and Chapman [5]. The A's were clustered on the left subgroup (green triangles), whereas the C's were clustered just to their right, but again as green triangles. Finally the B's tended to be clustered together next as green triangles on the right of subgroup one (Figure 6). On the left, most of
TABLE 3: Similarity percentage (SIMPER) contribution of polychaete species in each group (top two sets). Species that contributed to the dissimilarities between the groups at the bottom.

\begin{tabular}{lccc}
\hline Group & Species & Contri\% & Cum\% \\
\hline & Paraprionospio pinnata & 20.17 & 20.17 \\
1 (Av. Sim. & Mediomastus californiensis & 14.47 & 37.64 \\
$=48.32 \%)$ & Cossura soyeri & 12.73 & 47.37 \\
& Aricidea (Acmira) sp. & 11.57 & 58.94 \\
\hline & Paraprionospio pinnata & 8.55 & 8.55 \\
& Mediomastus californiensis & 8.02 & 16.57 \\
2 (Av. Sim. & Sthenelais sp. & 6.62 & 23.19 \\
$=46.98 \%)$ & Nereis micromma & 6.54 & 29.73 \\
& Cossura soyeri & 6.37 & 36.1 \\
\hline \multirow{3}{*}{ \& 2(Av. } & Nereis micromma & 3.7 & 3.7 \\
Dis.Sim. $=$ & Magelona sp. H & 2.86 & 6.56 \\
$64.30 \%)$ & Sthenelais sp. & 2.83 & 9.38 \\
& Tharyx annulosus & 2.8 & 12.18 \\
\hline
\end{tabular}

the group was close to the river mouth (A), whereas many in the next subgroup were at $\mathrm{C}$, the most distant location, with $\mathrm{B}$ in the middle of the transect. These species subgroups thus tended to reflect location rather than season or oxygen concentration. The distinctiveness of August 2012 at AB5, B, and $\mathrm{C}$ indicates that this period was also slightly different in species composition, as was inferred from the size data.

There was little evidence that the groups or subgroups were related to oxygen concentrations at the time of the sampling. For example, Group 2 (red dots) from August 2009 all grouped together but spanned a wide range of oxygen concentrations. The same can be stated for all the groups, on close inspection. Thus, species composition varied very little in time and space, but what variation did occur was not related to the oxygen concentration at the time of the sampling.

$P$. pinnata has long been recognized as the most common polychaete inhabiting the Gulf of Mexico hypoxic zone [53] and likewise its remarkable abundance dominated Groups 1 (18 branches) and 2 (three red branches) (Figure 6). P. pinnata and Mediomastus californiensis appeared in nearly every sample throughout the study and their abundance accounted for more than half of the total abundance everywhere. They contributed the most to the similarities within Group 1 and between Groups 1 and 2 (Table 2). The characteristic species of Group 1 (18 branches on the left of Figure 6) were all deposit feeders (both selective and nonselective), while Group 2 (branches with red dots) included carnivores, omnivores, and deposit feeders [55].

Nereis micromma contributed most to the dissimilarity between Groups 1 and 2 (3.7\%). It was not common in the 2004-05 samples; only two individuals were found during those first five cruises. In 2012 (the red dots of Figure 6) however 98 individuals were sampled (Table 3 ).

Abundance of $P$. pinnata increased from $555 \pm$ $764 \mathrm{inds} . / \mathrm{m}^{2}$ to $1131 \pm 1300$ and $1533 \pm 1157 \mathrm{inds} . / \mathrm{m}^{2}$ along the decreasing oxygen gradient. Abundance of $P$. pinnata under hypoxic conditions $(<2 \mathrm{mg} / \mathrm{L}$ and $<1 \mathrm{mg} / \mathrm{L})$ was 
significantly higher than that in oxic conditions $(p<0.05)$. Abundance however of $M$. californiensis was not different within the 3 oxygen levels.

\section{Discussion}

4.1. Effect of Hypoxia on Mean Animal Size. The results in terms of (a) the mean size of individual polychaetes (mg wet weight), (b) the biomass size spectra (BSS), and (c) the normalized biomass size spectra (NBSS) all demonstrate that animals were smaller under hypoxic conditions. Clearly, however, the northern Gulf of Mexico hypoxic area was not a "dead zone" as is often suggested in the popular media. Animals were small but not gone; in fact some were in great abundance when oxygen was low. The total biomass of the worms did not differ statistically throughout the wide range of conditions, even though mean sizes did vary.

A principal reason for the shift in mean size was exclusion of large-sized species that may be more vulnerable to low oxygen physiological stress [28], not a change in size within species [29]. Smaller species with a greater surface to volume ratio may be better able to cope with low oxygen than large species, with the exception of the medium-sized $P$. pinnata that may be able to survive because of its large branchial palps.

The positive relationship between size and oxygen agrees with the patterns observed by McClain and Rex [26] in turrid gastropods and "polar gigantism" in amphipod crustaceans [22]. Those environmental conditions however were at the high end of oxygen concentrations, so comparisons are not particularly relevant to physiological stress.

The general negative slope of an NBSS reflects biomass dominance by small size classes. The relative steepness (negativity) of the slope may be a reflection of stress if low oxygen stress favors small sizes. In our study, the NBSS slope ranged from -0.56 to -0.48 , but Quiroga et al. [34] reported a much broader range $(-0.481$ to -0.908$)$ in the oxygen minimum zone (OMZ) off Chile. The OMZ however is a more permanent condition that often approaches anoxia [35]. On the other hand, Saiz-Salinas and Romas [31] tabulated an even more negative NBSS slope along a depth gradient off Antarctica $(-0.76$ to -1.31$)$, but the latter reflects the commonly observed decrease in mean size of the macrobenthos which accompanies the decrease in available food as water depth increases $[17,19,20,56,57]$ and high mean sizes at shallow depths at high latitudes $[18,22]$.

\subsection{The Ubiquity of Paraprionospio pinnata and the "Altered"} NBSS. The lack of a significant negative regression in the NBSS when oxygen was lower than $1 \mathrm{mg} / \mathrm{L}$ was related to the impact on very small species but not on the ubiquitous $P$. pinnata. Generally, small-sized species tend to be relatively more abundant under stressful conditions $[13,36]$ and thus NBSS regression lines steepen as the larger animals are eliminated due to low oxygen stress; the smallest-sized polychaetes in size class -5 (Mediomastus californiensis, Aricidea (Acmira) sp., and Aricidea taylori) thus theoretically would be expected to be dominant [13]. But this was not the case. Low oxygen did depress the very small species but not $P$. pinnata. On the contrary, an increase in abundance of $P$. pinnata was encountered under moderate and severe hypoxia, reinforcing the findings of Baustian and Rabalais [54] at their station C6B.

Lamont and Gage [29] suggested that the enlargement in size and branching of the branchiae of the polychaete Paraprionospio sp. A on the continental slope off Oman were an adaptation to low oxygen in the oxygen minimum zone of the Arabian Sea. Morphological adaption of P. pinnata to low oxygen might be inferred from the inverse relationship with oxygen concentration noted by Rabalais et al. [53] and Baustian and Rabalais [54]. Our data agree that P. pinnata densities actually increased when subjected to hypoxia. It is reasonable to assume that their large branchial palps provide an enhanced ability to better scavenge oxygen at very low concentrations, but whether this is a phenotypic selection or genetic differentiation as implied by Lamont and Gage [29] remains as yet unknown [58].

The results of this study have implications for the oceanic biota as a whole. While the overall polychaete biomass (total grams, wet weight $\mathrm{m}^{-2}$ ) remained relatively high, mean size of assemblages declined in a continuum as oxygen decreased. Likewise, the overall ecological impact of low oxygen was to diminish both species richness and the diversity of individual size together at the same time at extreme conditions. While size in marine animals has increased over geologic time scales [59] in those habitats with a surfeit of oxygen, it must be acknowledged that size and diversity may also be decreasing as oxygen declines in many environments worldwide [8].

\section{Conflict of Interests}

The authors declare that there is no conflict of interests regarding the publication of this paper.

\section{Acknowledgments}

This study was supported by the Mechanisms Causing Hypoxia $(\mathrm{MCH})$ project at Texas A\&M University with funding from NOAA, Steve DiMarco, Principal Investigator (NOAA Center for Sponsored Coastal Research NA03N0S4780039 and NA06N0 S4780198). The authors are grateful to Dr. Matthew Howard for constructing the map. Fangyuan $\mathrm{Qu}$ was supported through the joint graduate education program agreement between the Department of Oceanography at Texas A\&M and Ocean University of China.

\section{References}

[1] N. N. Rabalais, R. E. Turner, and D. Scavia, "Beyond science into policy: gulf of Mexico hypoxia and the Mississippi River," BioScience, vol. 52, no. 2, pp. 129-142, 2002.

[2] Z. J. Quiñones-Rivera, B. Wissel, N. N. Rabalais, and D. Justic, "Effects of biological and physical factors on seasonal oxygen dynamics in a stratified, eutrophic coastal ecosystem," Limnology and Oceanography, vol. 55, no. 1, pp. 289-304, 2010.

[3] W. J. Wiseman, N. N. Rabalais, R. E. Turner, S. P. Dinnel, and A. Macnaughton, "Seasonal and interannual variability within the 
Louisiana coastal current: stratification and hypoxia," Journal of Marine Systems, vol. 12, no. 1-4, pp. 237-248, 1997.

[4] G. T. Rowe, "Seasonal hypoxia in the bottom water off the Mississippi River Delta," Journal of Environmental Quality, vol. 30, no. 2, pp. 281-290, 2001.

[5] G. T. Rowe and P. Chapman, "Continental shelf hypoxia: some nagging questions," Gulf of Mexico Science, vol. 20, pp. 153-160, 2002.

[6] R. E. Turner and N. N. Rabalais, "Coastal eutrophication near the Mississippi river delta," Nature, vol. 368, no. 6472, pp. 619$621,1994$.

[7] D. E. Harper Jr., L. D. McKinney, R. R. Salzer, and R. J. Case, "The occurrence of hypoxic bottom water off the upper texas coast and its effects of the benthic biota," Contributions of Marine Science, vol. 24, pp. 53-79, 1981.

[8] R. J. Diaz and R. Rosenberg, "Spreading dead zones and consequences for marine ecosystems," Science, vol. 321, no. 5891, pp. 926-929, 2008.

[9] G. R. Gaston, "Effects of hypoxia on macrobenthos of the inner shelf off Cameron, Louisiana," Estuarine, Coastal and Shelf Science, vol. 20, no. 5, pp. 603-613, 1985.

[10] R. Carvalho, C.-L. Wei, G. Rowe, and A. Schulze, "Complex depth-related patterns in taxonomic and functional diversity of polychaetes in the Gulf of Mexico," Deep-Sea Research I: Oceanographic Research Papers, vol. 80, pp. 66-77, 2013.

[11] A. J. Chivers, B. E. Narayanaswamy, P. A. Lamont, A. Dale, and R. Turnewitsch, "Changes in polychaete standing stock and diversity on the northern side of Senghor Seamount (NE Atlantic)," Biogeosciences, vol. 10, no. 6, pp. 3535-3546, 2013.

[12] C. F. Rakocinski, "Linking allometric macrobenthic processes to hypoxia using the Peters mass balance model," Journal of Experimental Marine Biology and Ecology, vol. 381, supplement, pp. S13-S20, 2009.

[13] E. P. White, S. K. M. Ernest, A. J. Kerkhoff, and B. J. Enquist, "Relationships between body size and abundance in ecology," Trends in Ecology and Evolution, vol. 22, no. 6, pp. 323-330, 2007.

[14] A. Clauset and D. H. Erwin, "The evolution and distribution of species body size," Science, vol. 321, no. 5887, pp. 399-401, 2008.

[15] A. E. Magurran, H. L. Queiroz, and A. P. Hercos, "Relationship between evenness and body size in species rich assemblage," Biology Letters, vol. 9, no. 6, Article ID 20130856, 2013.

[16] J. Damuth, "Of size and abundance," Nature, vol. 351, no. 6324, pp. 268-269, 1991.

[17] P. Polloni, R. Haedrich, G. Rowe, and C. Hovey Clifford, "The size-depth relationship in deep ocean animals," Internationale Revue der gesamten Hydrobiologie und Hydrographie, vol. 64, no. 1, pp. 39-46, 1979.

[18] G. Rowe, "The structure and function of Arctic benthic communities: are high-latitude ecosystems different?" Korean Journal of Polar Research, vol. 8, pp. 85-95, 1997.

[19] H. Thiel, "The size structure of the deep-sea benthos," Internationale Revue der Gesamten Hydrobiologie, vol. 60, pp. 576-606, 1975.

[20] H. Thiel, "Structural aspects of the deep-sea benthos," Ambio Special Report, vol. 6, pp. 25-31, 1979.

[21] K. Linse, D. K. A. Barnes, and P. Enderlein, "Body size and growth of benthic invertebrates along an Antarctic latitudinal gradient," Deep Sea Research Part II: Topical Studies in Oceanography, vol. 53, no. 8-10, pp. 921-931, 2006.

[22] G. Chapelle and L. S. Peck, "Polar gigantism dictated by oxygen availability, Nature, vol. 398, no. 6732, pp. 114-115, 1999.
[23] J. F. Harrison, A. Kaiser, and J. M. VandenBrooks, "Atmospheric oxygen level and the evolution of insect body size," Proceedings of the Royal Society B: Biological Sciences, vol. 277, no. 1690, pp. 1937-1946, 2010.

[24] M. E. Clapham and J. A. Karr, "Environmental and biotic controls on the evolutionary history of insect body size," Proceedings of the National Academy of Sciences of the United States of America, vol. 109, no. 27, pp. 10927-10930, 2012.

[25] J. F. Harrison and G. G. Haddad, "Effects of oxygen on growth and size: synthesis of molecular, organismal, and evolutionary studies with drosophila melanogaster," Annual Review of Physiology, vol. 73, pp. 95-113, 2011.

[26] C. R. McClain and M. A. Rex, "The relationship between dissolved oxygen concentration and maximum size in deep-sea turrid gastropods: an application of quantile regression," Marine Biology, vol. 139, no. 4, pp. 681-685, 2001.

[27] D. Singer, "Size relationship of metabolic rate: oxygen availability as the 'missing link' between structure and function?" Thermochimica Acta, vol. 446, no. 1-2, pp. 20-28, 2006.

[28] R. S. Etienne, S. N. de Visser, T. Janzen, J. L. Olsen, H. Olff, and J. Rosindell, "Can clade age alone explain the relationship between body size and diversity?" Interface Focus, vol. 2, no. 2, pp. 170-179, 2012.

[29] P. A. Lamont and J. D. Gage, "Morphological responses of macrobenthic polychaetes to low oxygen on the Oman continental slope, NW Arabian Sea," Deep-Sea Research Part II: Topical Studies in Oceanography, vol. 47, no. 1-2, pp. 9-24, 2000.

[30] B. E. Narayanaswamy, T. D. Nickell, and J. D. Gage, "Appropriate levels of taxonomic discrimination in deep-sea studies: species vs family," Marine Ecology Progress Series, vol. 257, pp. 59-68, 2003.

[31] J. I. Saiz-Salinas and A. Ramos, "Biomass size-spectra of macrobenthic assemblages along water depth in Antarctica," Marine Ecology Progress Series, vol. 178, pp. 221-227, 1999.

[32] R. W. Sheldon and T. R. Parsons, "A continuous size spectrum for particulate matter in the sea," Journal of the Fisheries Research Board of Canada, vol. 24, no. 5, pp. 909-915, 1967.

[33] R. M. Warwick and R. Price, "Macrofauna production in an estuarine mud flat," Journal of the Marine Biological Association of the United Kingdom, vol. 55, pp. 1-18, 1975.

[34] E. Quiroga, R. Quiñones, M. Palma et al., "Biomass size-spectra of macrobenthic communities in the oxygen minimum zone off Chile," Estuarine, Coastal and Shelf Science, vol. 62, no. 1-2, pp. 217-231, 2005.

[35] L. A. Levin, J. D. Gage, C. Martin, and P. A. Lamont, "Macrobenthic community structure within and beneath the oxygen minimum zone, NW Arabian Sea," Deep-Sea Research II: Topical Studies in Oceanography, vol. 47, no. 1-2, pp. 189-226, 2000.

[36] W. G. Sprules and M. Munawar, "Plankton size spectra in relation to ecosystem productivity, size, and perturbation," Canadian Journal of Fisheries and Aquatic Sciences, vol. 43, no. 9, pp. 1789-1794, 1986.

[37] T. Platt and K. Denman, "Organisation in the pelagic ecosystem," Helgoländer Wissenschaftliche Meeresuntersuchungen, vol. 30, no. 1-4, pp. 575-581, 1977.

[38] T. Platt and K. Denman, "The structure of pelagic ecosystems," Rapports et Procès-Verbaux des Réunions, vol. 173, pp. 60-65, 1978.

[39] T. H. Pearson and R. Rosenberg, "Macrobenthic succession in relation to organic enrichment and pollution of the marine environment," in Oceanography and Marine BiologyAn Annual Review, vol. 16, pp. 229-311, 1978. 
[40] S. Kerr and L. Dickie, The Biomass Spectrum: a Predator-Prey Theory of Aquatic Production, Columbia University Press, New York, NY, USA, 2001.

[41] P. Gómez-Canchong, J. M. Blanco, and R. A. Quiñones, "On the use of biomass size spectra linear adjustments to design ecosystem indicators," Scientia Marina, vol. 77, no. 2, pp. 257268, 2013.

[42] A. Quigg, J. B. Sylvan, A. B. Gustafson et al., "Going west: nutrient limitation of primary production in the northern Gulf of Mexico and the importance of the Atchafalaya River," Aquatic Geochemistry, vol. 17, no. 4, pp. 519-544, 2011.

[43] S. F. DiMarco, P. Chapman, N. Walker, and R. D. Hetland, "Does local topography control hypoxia on the eastern TexasLouisiana shelf?" Journal of Marine Systems, vol. 80, no. 1-2, pp. 25-35, 2010.

[44] L. Rovelli, M. Dengler, M. Schmidt, S. Sommer, P. Linke, and D. F. McGinnis, "Thermocline mixing and vertical oxygen fluxes in the stratified central North Sea," Biogeosciences Discussions, vol. 12, no. 13, pp. 9905-9934, 2015.

[45] S. Shivarudrappa, K. Briggs, and V. Hartmann, "Effects of hypoxia on the trophic structure of the polychaete communities in the northern Gulf of Mexico," in MTS/IEEE Kona Conference, OCEANS'11, usa, September 2011.

[46] K. B. Briggs, G. Cartwright, C. T. Friedrichs, and S. Shivarudruppa, "Biogenic effects on cohesive sediment erodibility resulting from recurring seasonal hypoxia on the Louisiana shelf," Continental Shelf Research, vol. 93, pp. 17-26, 2015.

[47] K. B. Briggs, V. A. Hartmann, K. M. Yeager et al., "Influence of hypoxia on biogenic structure in sediments on the Louisiana continental shelf," Estuarine, Coastal and Shelf Science, vol. 164, pp. 147-160, 2015.

[48] WOCE, "WOCE operating manual, WOCE operations and methods," WOCE Hydrographic Office Report WHPO 911/WOCE Report 68/91, WOCE, Woods Hole, Mass, USA, 1991.

[49] C. C. Nunnally, G. T. Rowe, D. C. O. Thornton, and A. Quigg, "Sedimentary oxygen consumption and nutrient regeneration in the Gulf of Mexico hypoxic zone," in Understanding and Predicting Change in the Coastal Ecosystems of the Northern Gulf of Mexico, J. C. Brock, J. A. Barras, and S. J. Williams, Eds., Journal of Coastal Research, Special Issue no.63, pp. 84-96, 2013.

[50] C. C. Nunnally, A. Quigg, S. DiMarco, P. Chapman, and G. T. Rowe, "Benthic-pelagic coupling in the Gulf of Mexico hypoxic area: sedimentary enhancement of hypoxic conditions and near bottom primary production," Continental Shelf Research, vol. 85, pp. 143-152, 2014.

[51] K. R. Clarke, P. J. Somerfield, and R. N. Gorley, “Testing of null hypotheses in exploratory community analyses: similarity profiles and biota-environment linkage," Journal of Experimental Marine Biology and Ecology, vol. 366, no. 1-2, pp. 56-69, 2008.

[52] K. R. Clarke and R. M. Warwick, Change in Marine Communities: An Approach to Statistical Analysis and Interpretation, PRIMER-E, Plymouth, UK, 2nd edition, 2001.

[53] N. N. Rabalais, L. E. Smith, D. E. Harper Jr., and D. Justic, "Effects of seasonal hypoxia on continental shelf benthos," in Coastal Hypoxia-Consequences for Living Resources and Ecosystems, N. N. Rabalais and R. E. Turner, Eds., vol. 58 of Coastal and Estuarine Studies, pp. 211-240, American Geophysical Union, 2001.

[54] M. M. Baustian and N. N. Rabalais, "Seasonal composition of benthic macroinfauna exposed to hypoxia in the northern Gulf of Mexico," Estuaries and Coasts, vol. 32, no. 5, pp. 975-983, 2009.

[55] K. Fauchald and P. A. Jumars, "The diet of worms: a study of polychaete feeding guilds," in Oceanography and Marine Biology-An Annual Review, vol. 17, pp. 193-284, Aberdeen University Press, Aberdeen, Scotland, 1979.

[56] M. Rex, R. J. Etter, J. S. Morris et al., "Global bathymetric patterns of standing stock and body size in the deep-sea benthos," Marine Ecology Progress Series, vol. 317, pp. 1-8, 2006.

[57] R. L. Haedrich and G. T. Rowe, "Megafaunal biomass in the deep sea," Nature, vol. 269, no. 5624, pp. 141-142, 1977.

[58] H. Yokohama and K. Tamai, "Four forms of the genus Paraprionospio (Polychaeta: Spionida) from Japan," Publications of the Seto Marine Biological Laboratory, vol. 26, no. 4-6, pp. 303-317, 1981.

[59] N. A. Heim, M. L. Knope, E. K. Schaal, S. C. Wang, and J. L. Payne, "Cope's rule in the evolution of marine animals," Science, vol. 347, no. 6224, pp. 867-870, 2015. 

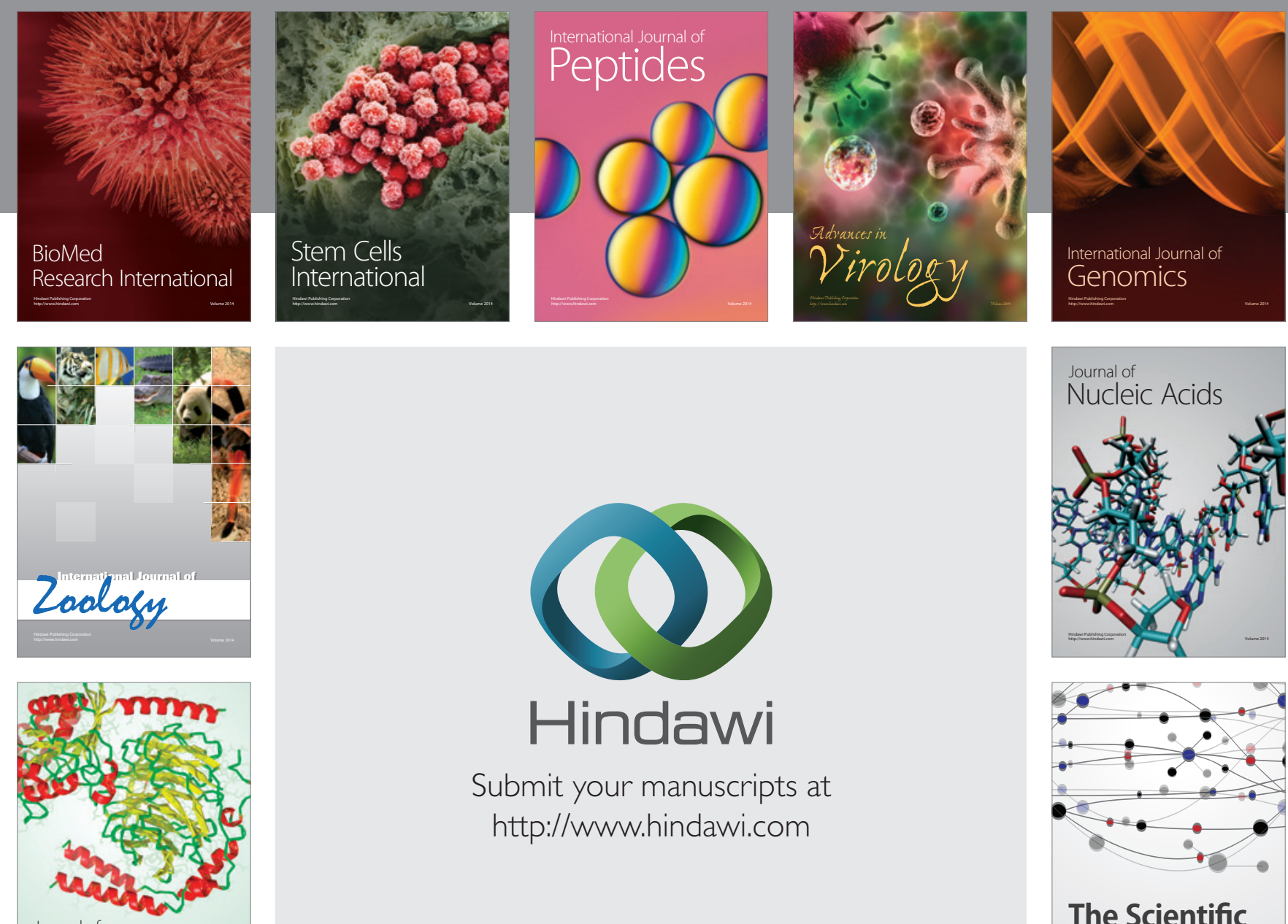

Submit your manuscripts at

http://www.hindawi.com

Journal of
Signal Transduction


The Scientific World Journal
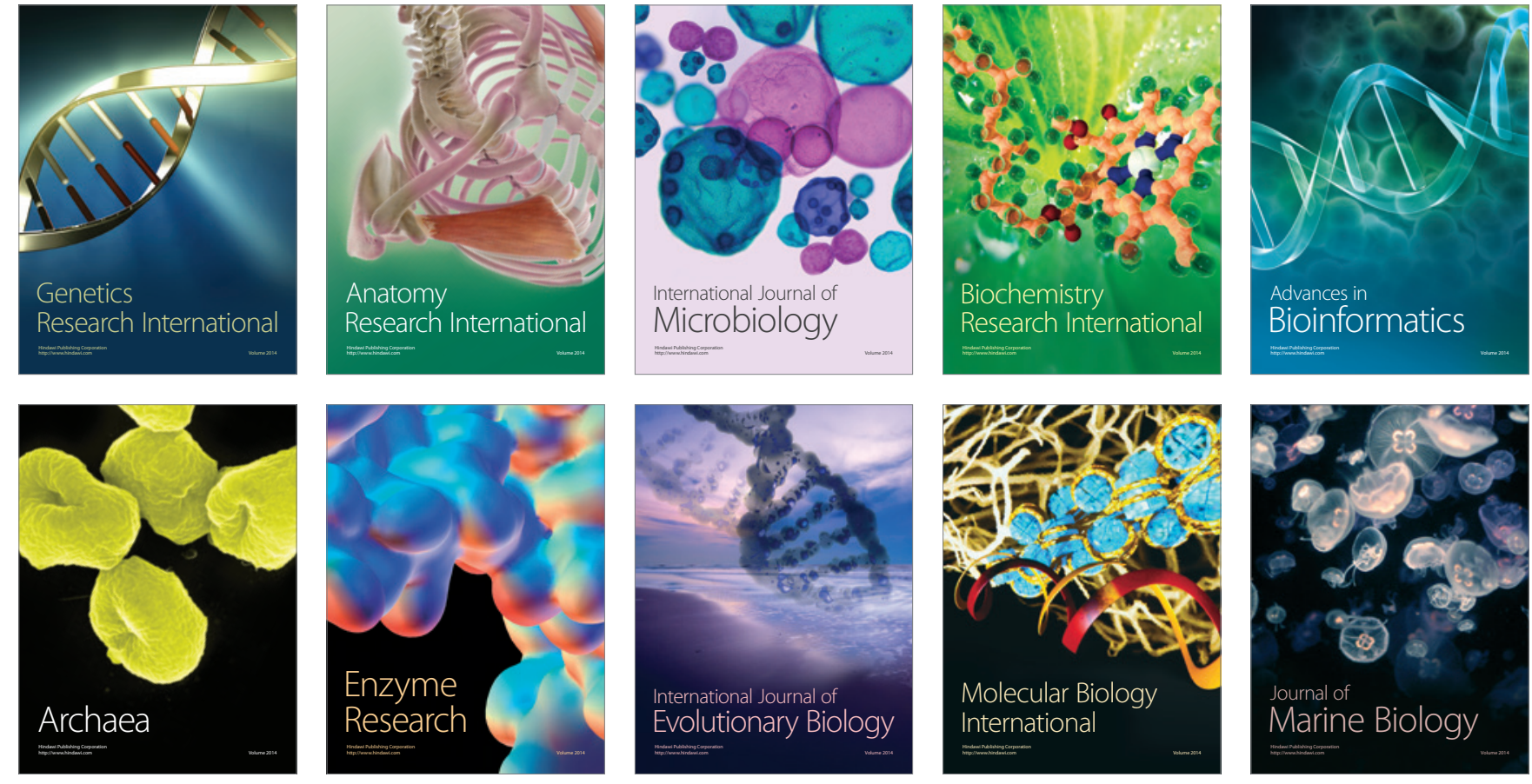